\title{
Reactive Stream Stabilization for Minimizing Transport of Phosphorus and Nitrogen from Agricultural Landscapes
}

\author{
Ji-Hee Son ${ }^{1}$, Chester C. Watson ${ }^{2}$, David S. Biedenharn ${ }^{2}$, Kenneth H. Carlson ${ }^{1}$ \\ ${ }^{1}$ Department of Civil and Environmental Engineering, Colorado State University, Fort Collins, USA \\ ${ }^{2}$ Biedenharn Group, Vicksburg, USA \\ E-mail: kcarlson@engr.colostate.edu \\ Received May 5, 2011; revised June 9, 2011; accepted July 8, 2011
}

\begin{abstract}
A reactive stream stabilization (RS2) system based on aluminum as the adsorbent and garden mulch as the organic matter source was designed to minimize release of agricultural nonpoint source pollutants and installed along the bank of the Little Bogue Creek, MS in 2008. The scope of this research was to design, install and assess the performance of a field scale RS2 structure based on results from previous lab scale studies. Concentrations of alum and total organic carbon (TOC) in the RS2 test barrier and surrounding area were measured to evaluate design parameters of RS2 and the removal effectiveness was examined from soils and monitoring wells that were sampled in 2009. The mean concentration of $\mathrm{Al}$ from the reactive barrier was 2.1 $\mathrm{mg} / \mathrm{g}$ and organic matter from the monitoring wells was $4.7 \mathrm{mg} / \mathrm{L}$, values significantly greater than the surrounding area $(\mathrm{p}<0.05)$. Soil Mehlich-3 $\mathrm{P}$ and total phosphorus (TP) were decreased by $55 \%$ and $30 \%$, and $40 \%$ of the TN and $51 \%$ of the nitrate in the ground water were removed through the RS2. The design objectives have been satisfied with the installed RS2 system and the initial sampling data shows effective nutrient removal.
\end{abstract}

Keywords: Phosphorus, Non-Point Source Pollutant, Best Management Practice, Aluminum

\section{Introduction}

Phosphorus is recognized as a limiting factor for growth of aquatic organisms in surface water bodies especially in lakes and reservoirs [1-3]. When excess amounts of nutrients (nitrogen and phosphorus) are discharged into surface water, the biomass of phytoplankton starts to increase and shifts to bloom-forming species that may be toxic to stock animals and potentially humans [4-7]. As biomass of algae increases, water transparency decreases and taste, odor and water treatment problems become a possibility [8]. Microorganisms decompose algae when they die resulting in dissolved oxygen depletion, death of living organisms, fish kills, and deterioration of aesthetic value of water bodies [9]. The USEPA has identified the excess release of nutrients as one of the top 5 causes of water quality "impairment" of rivers and streams in the U.S. along with pathogens, habitat alteration, organic enrichment, and unknown-impaired biota [10].

Phosphorus enters natural waters as a result of point source and nonpoint source pollution. Point sources are primarily discharges from wastewater treatment plants
(WWTPs), and nonpoint sources come from diffuse, difficult-to-identify, intermittent sources of pollutants such as urban and agricultural runoff [11]. Agricultural soils obtain P from livestock, mineral fertilizers, and municipal sludges and wastewaters resulting in a decrease of the soil's capacity to retain $\mathrm{P}$. The decreased $\mathrm{P}$ retention capacity of the soil can accelerate the loss of $\mathrm{P}$ into the watershed when there is heavy rainfall and runoff [12].

Unlike point source $\mathrm{P}$ loads which are typically treated through physical, chemical, and biological processes including adsorption and precipitation using alum, ferric chloride, and lime at wastewater treatment plants, nonpoint source $\mathrm{P}$ loads are largely controlled through "Best Management Practices (BMPs)", economical and technically feasible ways to minimize $\mathrm{P}$ movement [11]. Because of the tendency for phosphorus to sorb to soils, $\mathrm{P}$ usually moves with the soil or sediment during significant rainfall events [5,13-15]. Research has shown that within a landscape, 50 to 95 percent of $\mathrm{P}$ transports through moving sediments, recognized as the largest pollutant in our waters by volume and mass. Sediments are released into water bodies via bed and bank erosion, 
and overland erosion and therefore erosion control is a key method for decreasing nonpoint source $\mathrm{P}$ inputs to water bodies $[9,16]$. However, erosion control by itself will not be completely effective since a significant fraction of $\mathrm{P}$ is still in a colloidal or dissolved form particularly when high source loads decrease or eliminate the adsorption capacity of the soils and sediments.

River bank stabilization (RBS) and reactive stream stabilization (RS2) are both effective BMPs for reducing and preventing phosphorus from entering the watershed $[11,17]$. RBS can be installed alone or installed with RS2 to achieve additional amounts of phosphorus and nitrogen removal.

The RS2 is a system that is designed to stabilize the stream and minimize release of agricultural nonpoint pollutants from farms, waste sites, and animal feed lots to the stream through erosion. The RS2 diverts groundwater and surface water runoff through materials in the reactive barrier that enhance microbial and physical nutrient removal [17]. The nutrient removal efficiency of the RS2 system has been demonstrated by Watson's 2003 to 2006 study at the Colorado State University Engineering Research Center (ERC). Watson et al. (2006) found that the RS2 structure utilizing water treatment residual (WTR) as the reactive barrier material had the best phosphorus removal efficiency among the 3 evaluated materials; sawdust, WTR, and zero-valent iron (ZVI). WTR is an aluminum based media that is the residual from the coagulation and settling processes in a water treatment system and it has the capability of adsorbing large amounts of phosphorus [18-21]. When sand amended with $15 \%$ WTR was used as the reactive barrier, 98\% phosphorus removal and greater than $90 \%$ nitrate reduction was measured [17].

Based on the results of the field study at CSU, a RS2 structure was installed at a site along a stream bank of the Little Bogue Creek in Elliott, Mississippi in November 2008 (Figure 1).

The scope of the research was to assist in design and installation of a field scale RS2 structure and to conduct assessment of the initial nutrient removal performance of the system. For this research, the objectives that were established given the timeframe of the project were:

1) Assist in design and installation of field scale RS2 structure.

2) Document construction of RS2 structure and evaluate adherence to construction design parameters.

3) Provide initial data collection and evaluation of RS2 performance for limiting $\mathrm{P}$ and $\mathrm{N}$ transport to stream.

To evaluate design parameters of RS2, concentrations of alum and total organic carbon (TOC) in the RS2 test barrier and surrounding areas were analyzed to determine if enough of them are in the barrier to remove nutrients as it was designed.

\section{Methods}

After RS2 installation, soil and water samples were collected to begin understanding the structure's nutrient removal effectiveness. Sampled soils were classified and total phosphorus (TP), Mehilch-3 P, TOC, total nitrogen (TN) and aluminum (Al) were measured for soil concentrations and TP, dissolve reactive phosphorus (DRP), TN, nitrate and TOC were determined for water concentra-
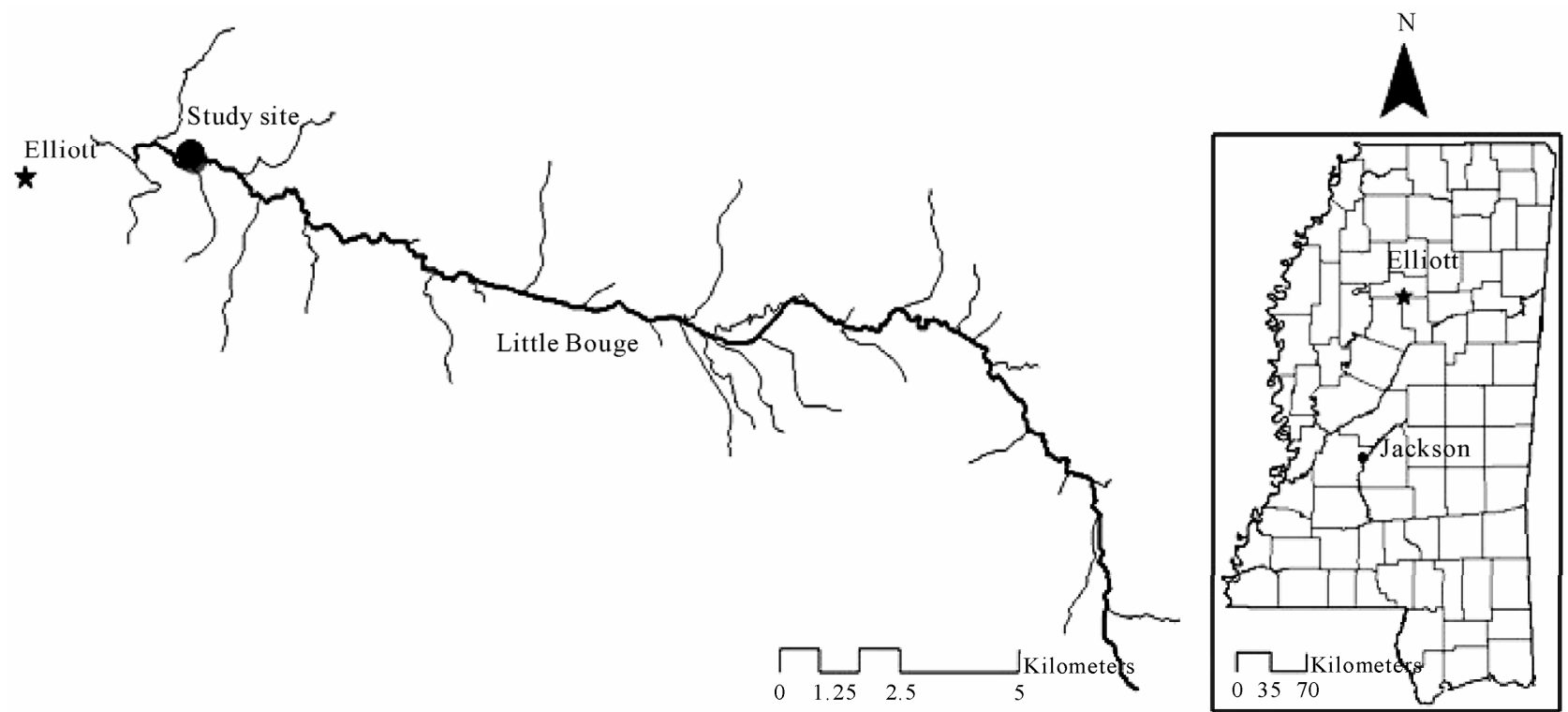

Figure 1. Map of the RS2 structure site on Little Bogue Creek in Elliott, MS (Data source: Mississippi geospatial clearinghouse). 
tions. A schematic diagram of the sampling sites is shown in Figure 2.

\subsection{Field Sampling}

Two sampling campaigns were conducted in 2009 (May and July) with soil and water samples being collected along the Little Bogue Creek in Elliot, Mississippi (Figure 2). Little Bogue creek is a well-suited place to study a RS2 system because it is surrounded by agricultural areas and the only expected source of nutrients in the stream is the nearby agricultural lands since there are no upstream WWTPs.

For the first sampling campaign, five soil samples (100 g per sample) were collected from both the lower bank of the barrier (Section 3; see Figure 2), upper bank of the barrier near the agricultural field (Section 1) and ten additional soil samples were taken from the reactive barrier (Section 2) at two different depths; 16 inches and 36 inches to observe differences and accumulation of $\mathrm{P}$. For the second sampling, five soil samples were collected from the lower bank of the barrier (Section 3), upper bank of the barrier near the field (Section 1) and the 16 inches deep reactive barrier (Section 2). Each soil sample was collected in a labeled plastic zip bag.

A well sampler was used to collect water samples from previously installed observation wells. The well sampler used was a rod-shape device 5 feet long that could be lengthened by 10 feet to reach ground water in the monitoring well. A volume of $0.5 \mathrm{~L}$ was taken from the monitoring wells LB2, LB3, LB4, LB5 and LB6, and four surface water samples were collected from upstream, adjacent to RS2 and downstream of the testing sites. Stream samples were collected from the center of the stream in clean, one liter Nalgene bottles.

After sampling, all of the samples were placed in ice bags to maintain low temperature $\left(<4^{\circ} \mathrm{C}\right)$ while they were transfered to the laboratory for analysis. Soil samples were air-dried, ground and passed through a 2-mm sieve before being transferred to a freezer. Water samples were filtered through Whatman No.42 filter paper then preserved in a refrigerator to avoid further reactions that could affect later measurement of the samples. All samples were measured within 28 days.

\subsection{Soil Classification}

Air-dried and ground soils were sieved through $2 \mathrm{~mm}$ (sieve No.10) and $75 \mu \mathrm{m}$ (sieve No.200) sieves to be characterized. The soils that did not pass through the 2 $\mathrm{mm}$ sieve were classified as gravel, the soils that passed through the $2 \mathrm{~mm}$ sieve but not the $75 \mu \mathrm{m}$ sieve were categorized as sand and the soils that went through the $75 \mu \mathrm{m}$ sieve were classified as silt and clay. The gravel, sand, and silt and clay fractions were weighed and classified using AASHTO soil classification system [22]. Soils were classified as silt-clay materials if more than 35 wt.\% of soils passed through the $75 \mu \mathrm{m}$ sieve and if less than $35 \mathrm{wt} \%$ passed the $75 \mu \mathrm{m}$ sieve, they were classified as granular materials. Most of the sampled soils were classified as silt-clay materials, the exceptions being 1-B and 2-A in Figure 2.

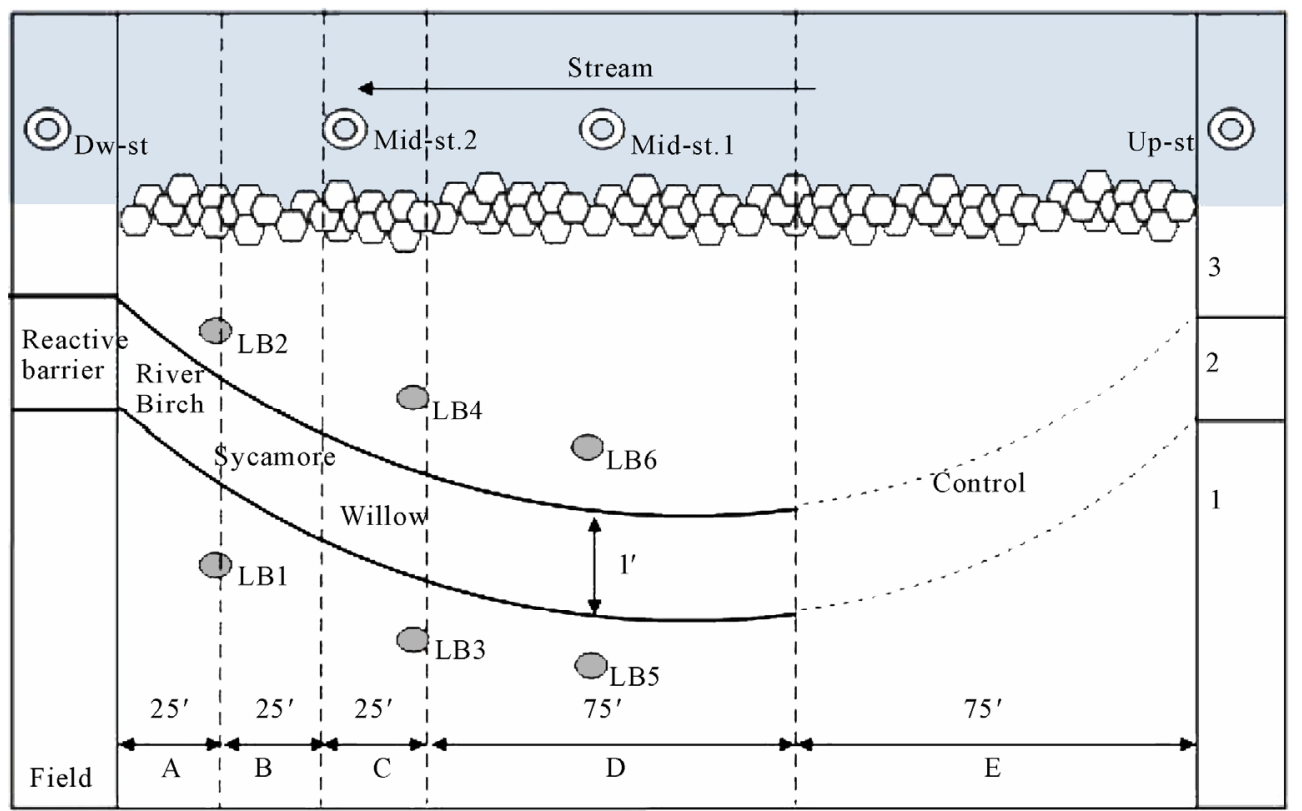

Figure 2. Plan view of sampling site in the RS2 test area on the Little Bogue Creek site (A, B, C, D: test area; E: control area; 1: field side upper bank; 2: RS2 barrier; 3: lower bank; LBs: monitoring wells). 


\subsection{Soil Analyses}

To understand the characteristics of $\mathrm{P}$ in the soil samples, two sediment-phosphorus analyses were conducted; TP and Mehlich-3 phosphorus. TOC and $\mathrm{Al}$ in the soils were also measured to help understand how these parameters impacted $\mathrm{P}$ adsorption. For the TP, TOC and $\mathrm{Al}$ analyses, a microwave digestion method was used [23]. The digestion method included an alkaline persulfate solution $(0.17 \mathrm{M} \mathrm{K} 2 \mathrm{~S} 2 \mathrm{O} 8+0.24 \mathrm{M} \mathrm{NaOH})$ that was prepared by mixing $11.25 \mathrm{~g}$ of potassium persulfate (Fisher scientific, Fair Lawn, NJ) and $59.5 \mathrm{ml}$ of $1 \mathrm{~N}$ sodium hydroxide (Fisher scientific, Fair Lawn, NJ) in a $250 \mathrm{~mL}$ volumetric flask with DI water. The vessel of the microwave digester was washed with $6 \mathrm{M} \mathrm{HCl}$ and DI water before and after the sample digestion. Each sample had $50 \mathrm{mg}$ of sediment digested for 40 minutes in the microwave digester for oxidation with $25 \mathrm{~mL}$ of alkaline persulfate oxidizing solution at $170^{\circ} \mathrm{C}$ and 135 psi. After 40 minutes, samples were cooled and vented in a fume hood, filtered through Whatman No.42 filter paper and then diluted to volume in $100 \mathrm{ml}$ volumetric flasks. The $\mathrm{pH}$ values of the extracts were adjusted to a range of 5-7.

Soil aluminum analysis was conducted using a Hach colorimetric method (Hach method No. 8012) and TP was analyzed using the ascorbic acid method with $10 \mathrm{ml}$ of digested extractant (Hach method No. 8048). Mehlich-3 $\mathrm{P}$ was measured for the bioavailable phosphorus [24] and TN was analyzed using the Shimadzu TOC-VCS analyzer (Shimadzu Corporation, Columbia, MD). The minimum detection limits (MDLs) of the methods for $\mathrm{Al}, \mathrm{TP}$, and $\mathrm{TN}$ are $0.008 \mathrm{mg} / \mathrm{L}, 0.03 \mathrm{mg} / \mathrm{L}$ [25], and $4 \mu \mathrm{g} / \mathrm{L}$, respectively.

\subsection{Aqueous Analyses}

For the aqueous analyses, TP, DRP, nitrate, TOC, and TN analyses were conducted. Water TP was measured using the Hach acid persulfate digestion method (Hach method No. 8190) and DRP was measured using the Phosver3 reagent (Hach Company, Loveland, CO; Hach method No. 8048). The cadmium reduction method was used for nitrate analysis (Hach method No. 8171) and TOC and TN were measured using the Shimadzu TOC-VCS analyzer (Shimadzu Corporation, Columbia, $\mathrm{MD})$.

\subsection{Statistical Method}

A paired t-test was used to study the correlation between the field and RS2 barrier, between the barrier and the bank, and between the field and the bank. Correlation of the RS2 test area and the control area were also tested at the $p=0.05$ significance level.

\section{Results and Discussion}

A demonstration-scale RS2 structure was designed and constructed along the west bank of the Little Bogue Creek in November, 2008. A combination of alum $(20 \%$ $\mathrm{v} / \mathrm{v})$ and organic matter as mulch $(19 \% \mathrm{v} / \mathrm{v})$ were mixed with the soil in the bank and river birch, sycamore and willow were used for pole plantings to prevent soil loss and improve the endurance of the RS2 structure.

\subsection{Design and Construction of the RS2}

The RS2 was designed according to previous field tests at the ERC of CSU from 2003 to 2006. For these tests, a mixture of $15 \%$ of WTR with sand was used in the reactive barrier and $98 \%$ phosphorus removal was achieved through the barrier. From the result of the test, 10 to 20 $\%$ volume fraction $(\mathrm{v} / \mathrm{v})$ of WTR and 15 to $20 \%$ of volume fraction $(\mathrm{v} / \mathrm{v})$ of mulch were targeted for the RS2 reactive barrier in the Little Bogue watershed.

Aluminum sulfate $\left(\mathrm{Al}_{2} \mathrm{SO}_{4}-14 \mathrm{H}_{2} \mathrm{O}\right)$ was used as a precursor of aluminum hydroxide $\left(\mathrm{Al}(\mathrm{OH})_{3}\right)$ formation in-situ. Eucalyptus mulch was applied as a source of organic matter $(\mathrm{OM})$ to provide electron donors for denitrification in the $150 \mathrm{ft}$ long reactive barrier. A $75 \mathrm{ft}$ long area adjacent to the barrier was used as a control section and it had no added aluminum or organic matter. Construction of the RS2 was completed in November, 2008 in a location where bank stabilization in the form of longitudinal peak stone toe protection (LPSTP) already existed. A 150 foot long, 4 foot deep and 1 foot wide trench was dug with a mini-excavator. Each 1.5 cubic foot bag of eucalyptus mulch was mixed with two 0.81 cubic foot bags of aluminum sulfate and native soils in the trench (Figure 3).

Since the weight fraction of aluminum was the main design criterion of the RS2 design for P adsorption, calculating the weight concentration of aluminum in the barrier was critical. Since the volume of trench was approximately 600 cubic feet, the volume percentage of $\mathrm{OM}$ and alum in trench were $18.7 \%$ and $20.2 \%$, respectively, and the corresponding weight percentage of aluminum should be $1.7 \%$. This weight percentage of aluminum was equivalent to $18 \% \mathrm{v} / \mathrm{v}$ of WTR since the weight fraction of aluminum in WTR is 0.094 .

After mixing alum and mulch with the native soils in the trench, poles of river birch, sycamore and willow were planted in increments of each 25 feet along the test trench and the rest of 75 feet of the trench remained without pole planting. To enhance infiltration of rain and surface runoff into the barrier, a small berm was built 


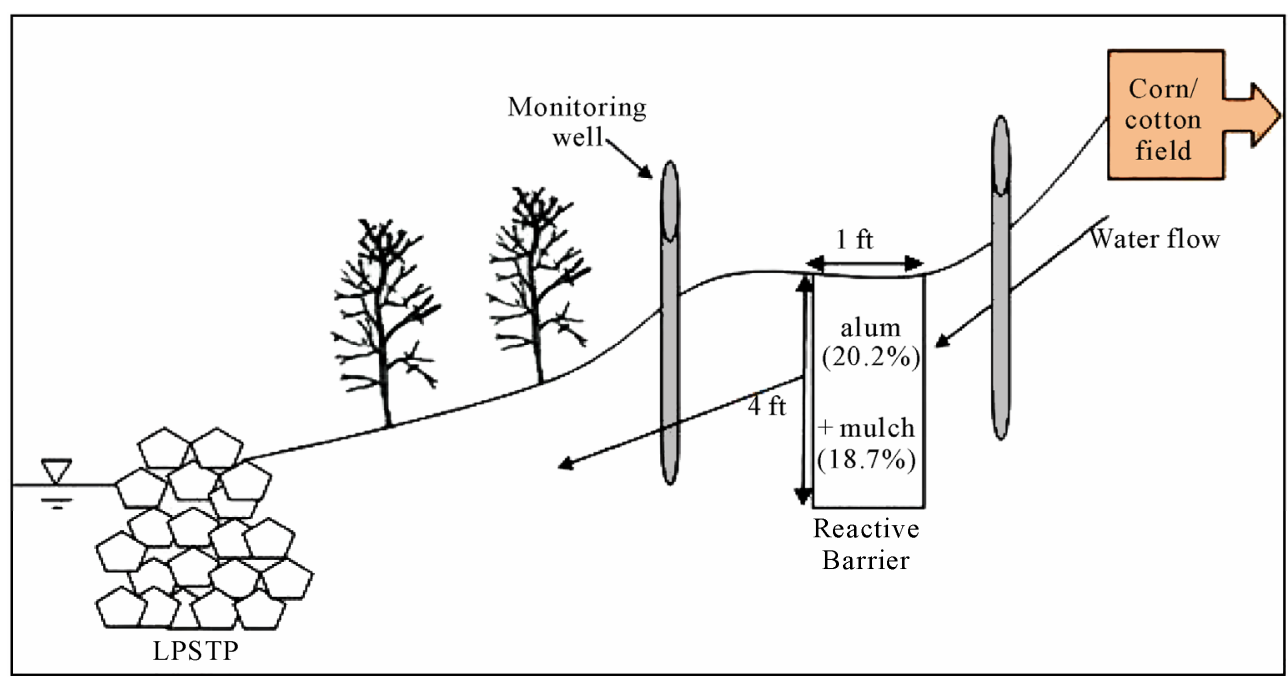

Figure 3. Design concept of RS2 in Little Bogue, MS.

stream-side of the trench and a gully on the top bank was restored. Excessive soils on the barrier, the berm and the repaired gully were removed and top soils were flattened and then seeded with winter rye grass and mulched hay.

Six monitoring wells were installed in January, 2009. Three of them were placed on the stream-side bank and three on the field side of the reactive barrier to monitor nutrients in the ground water passing through the barrier. Five months after the RS2 construction, the first sampling campaign was conducted in the test and control areas. Water samples were collected from the installed monitoring wells and the up-, mid- and down-stream sections of the creek. Soil samples were taken from the barrier and the stream bank on both the field-side and stream-side of the barrier. The second sampling campaign was carried out in July, 2009.

\subsection{Initial Monitoring Results}

\subsubsection{Soil Aluminum}

The primary design objectives of RS2 are to stabilize the stream bank, minimize bank erosion, and reduce phosphorus and nitrogen loads through the reactive barrier that contains aluminum to adsorb phosphorus and organic matter for facilitating denitrification. To achieve these design objectives, 20\% (by volume) of alum (1.7 weight $\%$ aluminum) and $19 \%$ (by volume) of mulch as organic matter were added in the reactive barrier with the bank soils. As shown in Figure 4, aluminum in the reactive barrier is five to ten times greater than the surrounding area and is significantly greater than the control area $(p<0.05)$. The mean concentration of aluminum in the reactive barrier is $2.1 \mathrm{mg} / \mathrm{g}$ (Coefficient of Variance = 0.49) whereas the mean concentrations in the adjacent field and bank are 0.67 and $0.46 \mathrm{mg} / \mathrm{g}$ and the concentra-

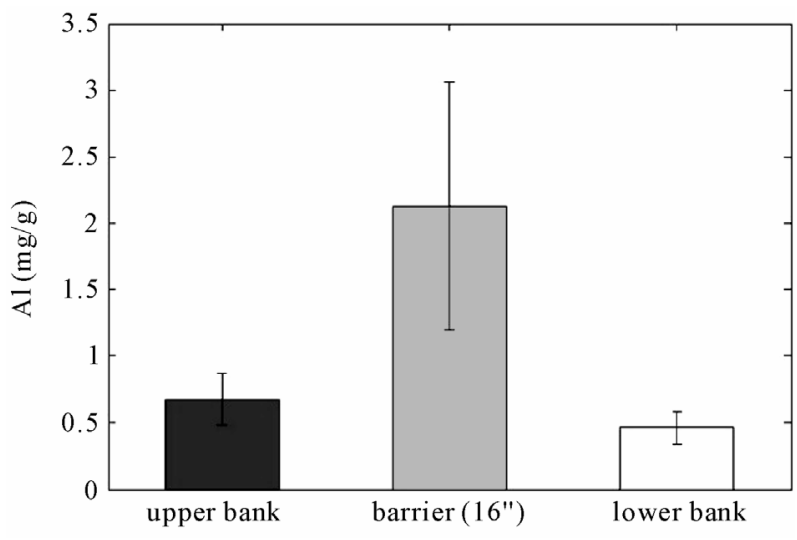

Figure 4. Concentrations (mg/g) of total aluminum in RS2 study area (error bars indicate $95 \%$ confidence intervals).

tion in the control area was measured to be $0.53 \mathrm{mg} / \mathrm{g}$. This compares with the design objective, based on labscale experiments of $1.7 \%$.

\subsubsection{Soil Phosphorus}

It can be expected that the concentration of phosphorus will decrease with the bank elevation when the stream bank is stable. As shown in Figure 5, the amount of total soil $\mathrm{P}$ tends to be reduced significantly from the upper bank to the lower bank in the study area $(p<0.05)$ but it is increased in the control area $(p=0.05$, statistically not significant). Since both the study and control areas have longitudinal stone toe bank stabilization, these results indicate that the reactive barrier has reduced the transport of $\mathrm{P}$ to the lower bank.

Mehlich-3 P is the loosely bound, plant-available phosphorus in the soil. Results from this study show that Mehlich-3 P constitutes only 10 to 20 percent of TP in the soil however it is a significant fraction of $\mathrm{P}$ since it is 


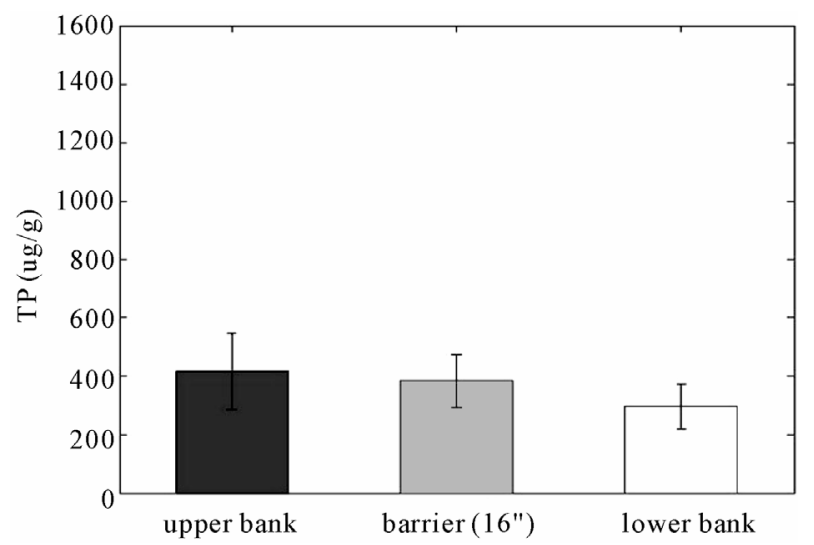

(a)

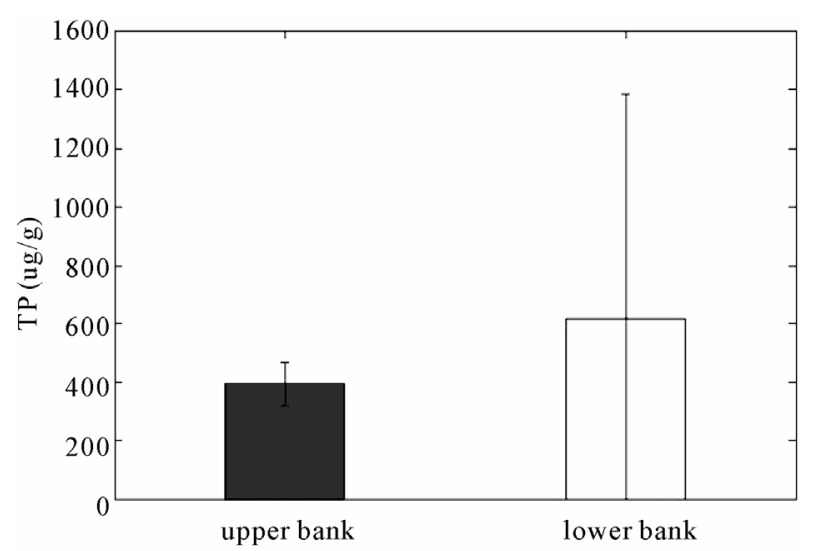

(b)

Figure 5. Concentrations ( $\mu \mathrm{g} / \mathrm{g}$ ) of soil TP in (a) RS2 study area and in (b) control area (error bars indicate $95 \%$ confidence intervals). (a) RS2 study area; (b) Control area.

bioavailable and can lead to eutrophication when present in excess. The mean of Mehlich-3 $\mathrm{P}$ of the field side from the reactive barrier is $50 \mu \mathrm{g} \mathrm{P} / \mathrm{g}$ soil as shown in Figure 6, a lower value than expected, although still in the optimum range for crop growth; $45-50 \mu \mathrm{g} / \mathrm{g}$ soil [26]. As shown in this figure, Mehlich-3 $\mathrm{P}$ is significantly less in the lower bank relative to the barrier and upper bank $(p<0.05)$. Mehlich-3 phosphorus was reduced from the field to the bank in the control area as well, but the range of the $95 \%$ confident interval is very wide and therefore more data is needed to draw a conclusion. The results also show that Mehlich-3 $\mathrm{P}$ at the 36-inch depth is $17 \mu \mathrm{g} / \mathrm{g}$ higher than at the 16-inch depth barrier (Figure 7). These results indicate that leaching of Mehlich-3 phosphorus may be occurring causing the higher concentration at the lower depth.

The $\mathrm{P}$ results from Figures 5-7 are summarized in Table 1. Soil TP was reduced through the RS2 barrier by $30 \%$ of the mean value from the field to the bank whereas the concentration increased by $58 \%$ from field to bank in the control area. Concentrations of Mehlich-3

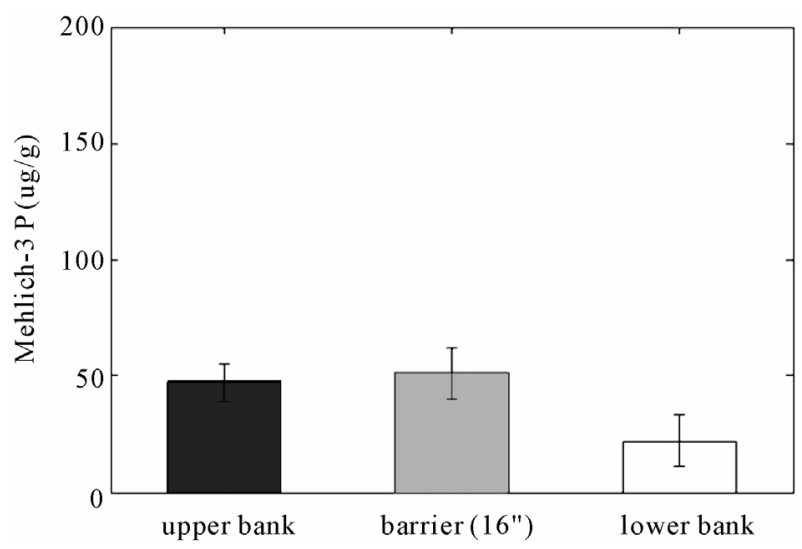

(a)

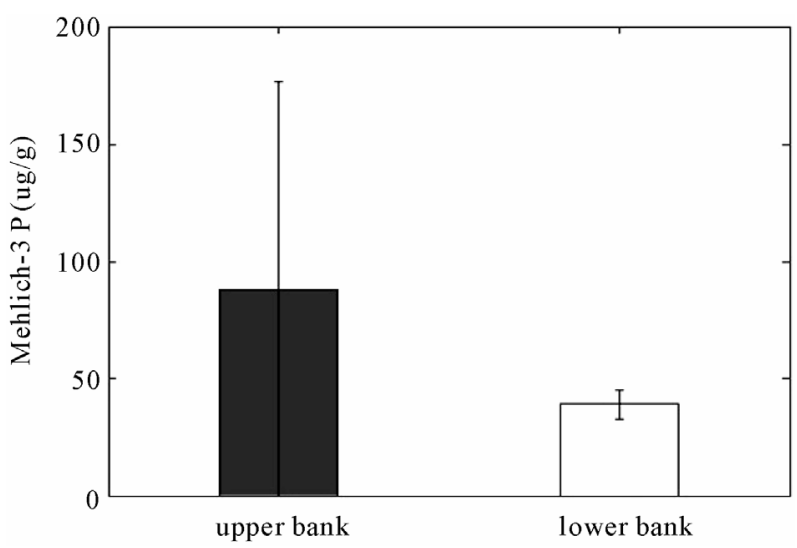

(b)

Figure 6. Concentrations ( $\mu \mathrm{g} / \mathrm{g}$ ) of Mehlich-3 $\mathrm{P}$ in (a) RS2 study area and in (b) control area (error bars indicate $95 \%$ Confidence Intervals). (a) RS2 study area; (b) Control area.

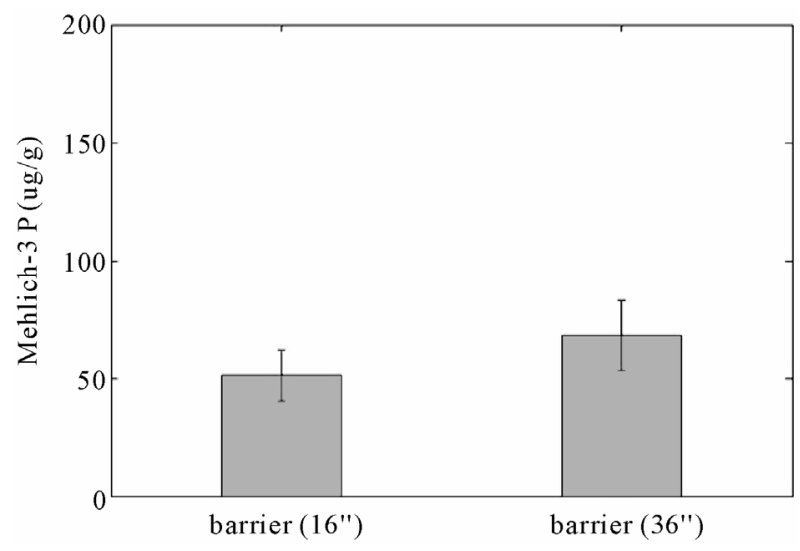

Figure 7. Concentrations $(\mu \mathrm{g} / \mathrm{g})$ of Mehlich-3 $P$ in the two depths; 16 inches and 36 inches of the reactive barrier (error bars indicate $95 \%$ confidence intervals).

phosphorus were significantly decreased by $55 \%$ of mean value from the field to the bank in the RS2 study area and in the control area as well. The sample size of the control area was not enough to confidently represent 
mean concentration of phosphorus since the range of $95 \%$ C.I. is too wide.

\subsubsection{Water Concentrations}

Concentrations of TP, DRP, TN, $\mathrm{NO}_{3}^{-}$and TOC were determined for the water samples collected from the six monitoring wells (Figure 8). The TOC concentration across the reactive barrier was significantly higher than the field area. As a result of adding garden mulch into the RS2 barrier, the concentration of TOC in the bank well was $590 \%$ greater than the TOC in the field well. $\mathrm{TN}$ and nitrate $\left(\mathrm{NO}_{3}^{-}\right)$concentrations showed 40 and $51 \%$ reductions (statistically not significant) from 1.78 and $0.95 \mathrm{mg} / \mathrm{L}$ to 1.14 and $0.47 \mathrm{mg} / \mathrm{L}$ through the reactive barrier, respectively.

These results support one of the key design objectives of the RS2 structure, the addition of electron donating organic matter in the reactive zone and the associated denitrification of nitrate.

DRP reduction in the monitoring wells (14\%) was lower than the soil TP and Mehlich-3 P that were reduced by $30 \%$ and $55 \%$, respectively, across the barrier. The lower reduction in the aqueous phase likely is due to the relatively higher concentration of $\mathrm{P}$ in the solid phase (300 ppm versus $<0.3 \mathrm{ppm}$ aqueous) and the concentrating effect of the RS2 barrier.

In Figure 9, TOC decreased along the stream although organic matter was added in the barrier and the downgradient monitoring wells showed elevated TOC levels. Therefore, it appears that the added TOC does not measurably impact the stream.

Table 1. Soil TP and Mehlich-3 $P$ reductions (\%) in RS2 structure (mean $\pm \mathbf{9 5 \%}$ C.I.) and significant levels of difference between upper and lower banks based on the paired t-test.

\begin{tabular}{ccccc}
\hline & \multicolumn{2}{c}{ TP $(\mathrm{mg} / \mathrm{g})$} & \multicolumn{2}{c}{ Mehlich-3 P (mg/g) } \\
\cline { 2 - 5 } & RS2 & Control & RS2 & Control \\
\hline Upper bank & $0.41 \pm 0.13$ & $0.39 \pm 0.07$ & $0.05 \pm 0.01$ & $0.09 \pm 0.09$ \\
Lower bank & $0.30 \pm 0.08$ & $0.62 \pm 0.78$ & $0.02 \pm 0.01$ & $0.04 \pm 0.01$ \\
Reduction (\%) & 30 & +58 & 55 & 55 \\
$\begin{array}{c}\text { P (significant } \\
\text { level) }\end{array}$ & 0.0001 & 0.5000 & 0.0088 & 0.1476 \\
\hline
\end{tabular}

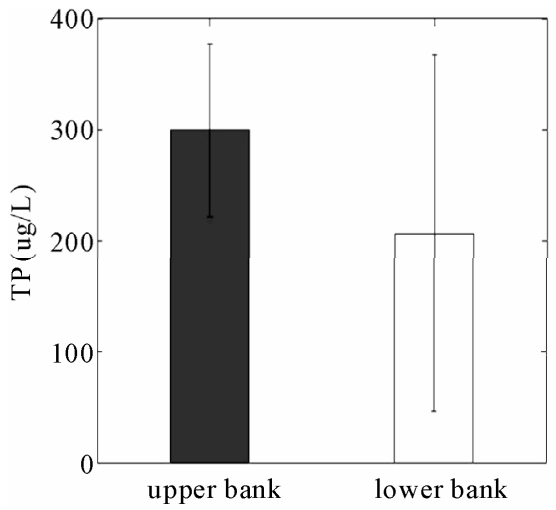

(a)

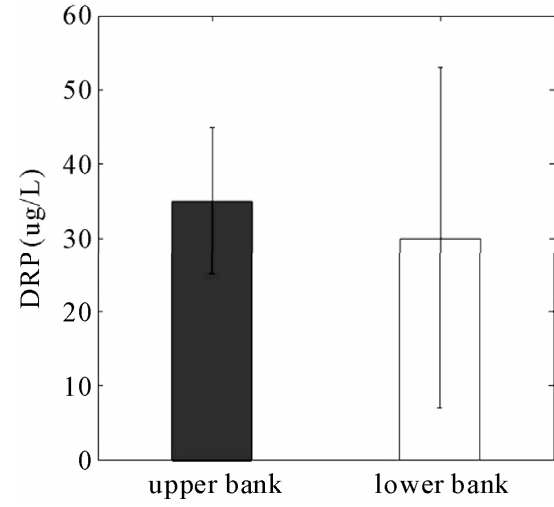

(b)

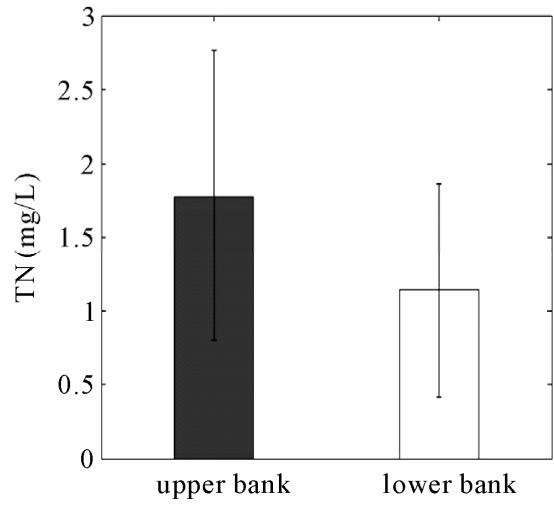

(c)

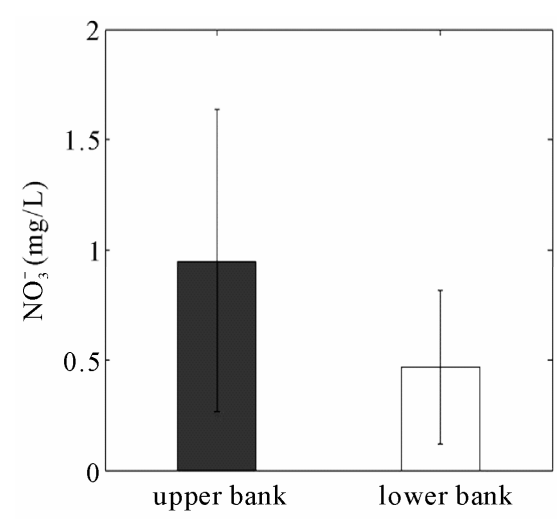

(d)

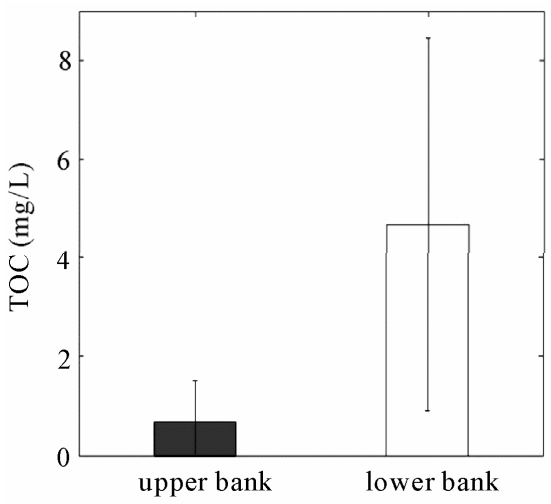

(e)

Figure 8. Concentration of (a) TP, (b) DRP, (c) TN, (d) nitrate and (e) TOC in waters from monitoring wells in upper and lower banks (error bars indicate $95 \%$ confidence intervals). 


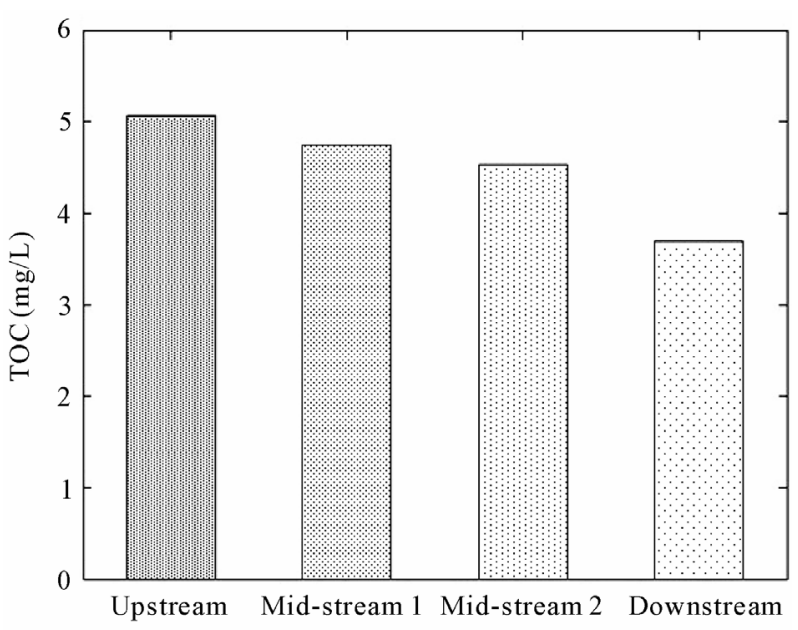

Figure 9. Concentrations (mg/L) of TOC in stream.

From this study, the construction and design objecttives of RS2 appear to have been satisfied since aluminum and TOC concentrations in the RS2 barrier were significantly higher than the adjacent areas $(p<0.05)$. Preliminary monitoring of nutrient-removal-efficiency of the RS2 barrier has provided promising results although more study is needed to draw significant conclusions.

\section{Conclusions}

Soil $\mathrm{P}$ losses from agriculture are one of the biggest sources of eutrophication in surface waters transport of $P$ through subsurface flow cannot be ignored [5]. The RS2 structure was developed to stabilize the stream bank, remove $\mathrm{N}$ and prevent $\mathrm{P}$ losses from agricultural lands. As it was designed, soils in the reactive barrier studied in this research contain substantially greater amounts of aluminum than the surrounding area and high concentrations of TOC to facilitate denitrification. At this point, $\mathrm{P}$ and $\mathrm{N}$ reductions are not as high as observations in field tests at CSU but it are still considerable. From this research, the design objectives of RS2 have been achieved and we expect continued improvement in removal efficacy. Therefore, RS2 should be seen as another P and N load reduction BMP that might be applicable for non-point source nutrient control.

\section{Acknowledgements}

The authors would like to acknowledge the ongoing support of the US Army Corps of Engineers - Vicksburg District for this study. The work was carried out as part of the Delta Headwaters Project under the direction of John Smith and David Derrick. Additional data from this site and additional applications will be reported on through this project in the future.

\section{References}

[1] N. N. Rabalais, "Nitrogen in Aquatic Ecosystems," Ambio, Vol. 31, No. 2, 2002, pp. 102-112.

[2] D. W. Schindler, R. E. Heckey, D. L. Findlay, M. P. Stainton, B. R. Parker, M. J. Paterson, K. G. Beaty, M. Lyng and S. E. M. Kasian, "Eutrophication of Lakes cannot be Controlled by Reducing Nitrogen Input: Results of a 37-Year Whole-Ecosystem Experiment," Proceedings of the National Academy of Sciences, Vol. 105, No. 32, 2008, pp. 11254-11258. doi:10.1073/pnas.0805108105

[3] S. R. Carpenter, "Phosphorus Control is Critical to Mitigating Eutrophication," Proceedings of the National Academy of Sciences, Vol. 105, No. 32, 2008, pp. 11039 11040. doi: $10.1073 /$ pnas.0806112105

[4] R. H. Foy and P. J. A. Withers, "The Contribution of Agricultural Phosphorus to Eutrophication," Proceedings of the Fertilizer Society, No. 365, 1995, pp. 1-32.

[5] B. L. Turner and P. M. Haygarth, "Phosphorus Forms and Concentrations in Leachate under Four Grassland Soil Types," Soil Science Society of America Journal, Vol. 64, No. 3, 2000, pp. 1090-1099. doi:10.2136/sssaj2000.6431090x

[6] K. Sivonen, "Cyanobacterial Toxins," In: M. Schaechter, Ed., Enclopedia of Microbiology 3rd Edition, Elsevier, Oxford, 2009, pp. 290-307. doi:10.1016/B978-012373944-5.00005-5

[7] J. Zhang, W. Ni, Y. Luo, R. J. Stevenson and J. Qi, "Response of Freshwater Algae to Water Quality in Qinshan Lake within Taihu Watershed, China," Physics and Chemistry of the Earth, Vol. 36, No. 9-11, 2011, pp. 360-365.

[8] J. Domagalski, C. Lin, Y. Luo, J. Kang, S. Wang, L. R. Brown and M. D. Munn, "Eutrophication Study at the Panjiakou-Daheiting Reservoir System, Northern Hebei Province, People's Republic of China: Chlorophyll-a Model and Sources of Phosphorus and Nitrogen," Agricultural Water Management, Vol. 94, No. 1-3, 2007, pp. 43-53.

[9] L. Oldham, "Phosphorus in Mississippi Soils," Information Sheet 871, Mississippi State University Extension Service, Stoneville, 2008.

[10] USEPA, "National Water Quality Inventory: Report to Congress 2004 Reporting Cycle," Office of Water, U.S. Environmental Protection Agency, Washington D.C., EPA-841-R-08-001, 2009.

[11] V. Novotny, "Water Quality: Diffuse Pollution and Watershed Management," John Wiley \& Sons, Hoboken, 2002.

[12] P. M. Haygarth and S. C. Jarvis, "Agriculture, Hydrology and Water Quality," CABI, Wallingford, 2002. doi:10.1079/9780851995458.0000

[13] R. W. McDowell, A. N. Sharpley, L. M. Condron, P. M. Haygarth and P. C. Brookes, "Processes Controlling Soil Phosphorus Release to Runoff and Implications for Agricultural Management," Nutrient Cycling in Agroecosys- 
tems, Vol. 59, No. 3, 2001, pp. 269-284. doi:10.1023/A:1014419206761

[14] National Research Council, "Mississippi River Water Quality and the Clean Water Act," The National Academies Press, Washington D.C., 2008.

[15] N. S. Rao, Z. M. Easton, E. M. Schneiderman, M. S. Zion, D. R. Lee and T. S. Steenhuis, "Modeling Watershed-Scale Effectiveness of Agricultural Best Management Practices to Reduce Phosphorus Loading," Journal of Environmental Management, Vol. 90, No. 3, 2009, pp. 1385-1395. doi:10.1016/j.jenvman.2008.08.011

[16] K. M. Frothingham, "Evaluation of Stability Threshold Analysis as a Cursory Method of Screening Potential Streambank Stabilization Techniques," Applied Geography, Vol. 28, No. 2, 2008, pp. 124-133. doi:10.1016/j.apgeog.2007.07.006

[17] C. C. Watson, K. H. Carlson and B. A. Jordan, "Delta Headwaters Project Monitoring Sites 2006 Evaluation," Cottonwood Research LLC, Fort Collins, 2006.

[18] L. E. Gallimore, N. T. Basta, D. E. Storm, M. E. Payton, R. H. Huhnke and M. D. Smolen, "Water Treatment Residual to Reduce Nutrients in Surface Runoff from Agricultural Land," Journal of Environment Quality, Vol. 28, No. 5, 1999, pp. 1474-1478. doi:10.2134/jeq1999.00472425002800050012x

[19] G. K. Haustein, T. C. Daniel, D. M. Miller, P. A. Moore and R. W. McNew, "Aluminum-Containing Residuals Influence High-Phosphorus Soils and Runoff Water Quality," Journal of Environmental Quality, Vol. 29, No. 6, 2000, pp. 1954-1959.

\section{doi:10.2134/jeq2000.00472425002900060031x}

[20] H. A. Elliott, G. A. O'Connor, P. Lub and S. Brintonb, "Influence of Water Treatment Residuals on Phosphorus Solubility and Leaching." Journal of Environment Quality, Vol. 31, No. 4, 2002, pp. 1362-1369. doi:10.2134/jeq2002.1362

[21] J. A. Ippolito, K. A. Barbaricka, D. M. Heila, J. P. Chandlerb and E. F. Redenteb, "Phosphorus Retention Mechanisms of a Water Treatment Residual," Journal of Environmental Quality, Vol. 32, No. 5, 2003, pp. 1857-1864. doi: $10.2134 /$ jeq2003.1857

[22] C. A. Hogentogler and K. Terzaghi, "Interrelationship of Load, Road and Subgrade," Public Roads, Vol. 10, 1929, pp. 37-64.

[23] S. E. Littau and W. G. Engelhart, "Microwave Sample Preparation for Total Nitrogen and Phosphorus Determination," CEM Corporation, Matthews, 1990.

[24] A. Mehlich, "Mehlich 3 Soil Test Extractant: A Modification of Mehlich 2 Extractant," Communications in Soil Science and Plant Analysis, Vol. 15, No. 12, 1984, pp. 1409-1416. doi:10.1080/00103628409367568

[25] M. Yarkin, "Enhancing Natural Treatment Systems by Utilizing Water Treatment Residuals," Ph.D. Dissertation, Colorado State University, Fort Collins, 2008.

[26] J. T. Sims, "Soil Test Phospohrus: Mehlich 3," In: G. M. Pierzynski, Ed., Method of Phosphorus Analysis for Soils, Sediments, Residuals, and Waters, Southern Cooperative Series Bulletin No. 396, 2000. 